\title{
Evaluation of Dielectric Barrier Discharge Sterilization of Escherichia coli with a Swept- Wavelength Resonance-Raman Device
}

\author{
Nagapratima Kunapareddy, ${ }^{1}$ Danil Dobrynin, ${ }^{2}$ Gary Friedman, ${ }^{2}$ \\ Alexander Fridman, ${ }^{2}$ Gregory Fridman, ${ }^{2} \&$ Jacob Grun ${ }^{3}$
}

\begin{abstract}
${ }^{1}$ Research Support Instruments, Lanham, Maryland; ${ }^{2}$ A. J. Drexel Plasma Institute, Drexel University, Philadelphia, Pennsylvania; ${ }^{3}$ Plasma Physics Division, Naval Research Laboratory, Washington, District of Columbia

*Address all correspondence to: Jacob Grun, Jacob.Grun@nrl.navy.mil

ABSTRACT: We show data indicating that resonance-Raman spectroscopy can distinguish live Escherichia coli bacteria from E. coli killed by a nanosecond-pulsed dielectric barrier discharge. The observations may result in an in situ, real-time method of monitoring sterilization efficacy.
\end{abstract}

KEY WORDS: Raman, SWOrRD, resonance-Raman, sterilization, dielectric barrier discharge

\section{INTRODUCTION}

Cold atmospheric pressure plasmas are now being widely used for many types of surface disinfection and sterilization. ${ }^{1-6}$ Of special interest is the use of plasmas as a rapid, additive-free disinfectant in a medical setting, where plasma is applied directly to living tissue without damaging it. One of the key challenges of plasma treatments in medicine is assessing its effectiveness as a function of depth in tissue morphology, wound morphology, or both. Recently, fluorescent spectroscopy was used to show that reactive oxygen species created by a plasma generated with a floating-electrode dielectric barrier discharge (FE-DBD) penetrate 5-7 mm of tissue, depending on the type of tissue. ${ }^{7}$ Nevertheless, direct measurements of sterilization inside of tissue and wound coagulum are yet to be addressed.

Multiple-wavelength, resonance-Raman spectroscopy has been shown to distinguish between different types of bacteria ${ }^{8}$ and can detect the presence of chemicals in complex backgrounds. ${ }^{9}$ We show here that it also can distinguish live Escherichia coli bacteria from $E$. coli killed by a dielectric barrier discharge. If this observation is confirmed for different bacterial species, and if the technique can be shown to work in tissue and wound coagulum at depths similar to those at which plasma discharges are effective, then rapid, in situ detection of sterility during FE-DBD plasma sterilization treatment would become feasible. The work presented here is a first step in this direction.

In the experiments described herein, sterilization of $E$. coli on the surface of agar was accomplished with an FE-DBD plasma discharge. FE-DBD plasma is generated through the application of nanosecond, high-voltage pulses $(\sim 30 \mathrm{kV}$; rise time, $<20$-ns pulse 
width) between the quartz-covered electrode and the agar plate, as was described by the authors previously. ${ }^{1,10,11}$ The gap between the electrode and the agar is set to 1-2 $\mathrm{mm}$ and the pulse is applied with a $1-\mathrm{kHz}$ repetition rate. Because the breakdown voltage in air in room conditions is approximately $3 \mathrm{kV} / \mathrm{mm}(\sim 30 \mathrm{kV} / \mathrm{mm}$ is applied in our case), such significant overvoltage leads to overlap of plasma filaments, ${ }^{12-14}$ providing for overall plasma uniformity in the discharge gap, independent of electrode morphology. ${ }^{15,16}$ Uniform FE-DBD plasmas recently have been shown to be effective antimicrobial agents of interest to hospitals. FE-DBD has been shown to sterilize surfaces in a hospital setting, ${ }^{17,18}$ in air, ${ }^{19}$ in water, ${ }^{17,20}$ and, especially, to sterilize a human patient. ${ }^{1,10,11,21}$ FE-DBD has been shown to promote wound healing during the 3 major wound repair phases: (1) blood coagulation, ${ }^{10,22}$ (2) wound coagulum sterilization, ${ }^{23-26}$ and (3) initiation of wound repair mechanisms such as fibroblast proliferation and growth factor release. ${ }^{27}$ Determination of whether the $E$. coli bacteria on the agar were viable was made by plating the treated bacteria on nutrient agarose gel and incubating the culture overnight. In addition, multiwavelength, resonance-Raman spectra of untreated bacteria and bacteria after plasma treatment were acquired and compared. The spectra were acquired with the Swept-Wavelength Optical resonance-Raman Device (SWOrRD), which is a stimulated spectroscopy system capable of rapidly acquiring spectral signatures of samples illuminated by laser wavelengths between 210 and $1700 \mathrm{~nm}$ in steps as small as $0.1 \mathrm{~nm}$. Because the illumination light in this wavelength range is resonant with bacteria, spectra acquired at distinct illumination wavelengths contain information reflecting variations in resonance cross-sections with illumination wavelength. Therefore, with these spectra it should be more difficult to confuse identification of bacteria in complex environments, such as those present in tissues and wounds. We have shown, in fact, that this is the case for chemicals. ${ }^{8}$

\section{EXPERIMENTAL METHODS AND PROCEDURES}

\section{A. Nanosecond-Pulsed FE-DBD}

The FE-DBD system is based on a conventional DBD and basically is a system driven by a pulsed high voltage applied between 2 conductors, with one or both covered with a dielectric to prevent transition to arc. In this setup, the amplitude and waveform of the high voltage signal are quite important. It is widely known that damage to a surface being treated is related to the temperature of the filaments, their density, and the energy per filament. ${ }^{15,16,28,29}$ Uniformity of FE-DBD treatment has been discussed elsewhere ${ }^{15,30}$ and can range from a rather nonuniform, continuous wave discharge to a uniform, nanosecond-pulsed plasma. A continuous-wave system can have different waveforms (e.g., sin, triangle), with 1 to $30 \mathrm{kHz}, 10$ to $40 \mathrm{kV}$ peak to peak: microsecond pulse system (single polarity positive pulse, duration of $2 \mu \mathrm{sec}$, rise time of $5 \mathrm{~V} / \mathrm{nsec}$, pulse frequency of 120 $\mathrm{Hz}$ to $4 \mathrm{kHz}$ ) or a nanosecond pulse system (duration of 20-40 nsec, rise time of 1-3 $\mathrm{kV} / \mathrm{nsec}$, a single pulse to $2 \mathrm{kHz}$ ). ${ }^{10,15,16,1}$ The continuous-wave discharge has the lowest number of filaments while operating at the highest power and temperature and was 
shown to significantly damage biological tissues being treated, ${ }^{10,16}$ whereas nanosecondpulsed systems deliver a uniform plasma at near room temperature $(300 \mathrm{~K}$, measured spectroscopically). ${ }^{15,16}$ The electrical safety of the application of plasma to living tissue has been discussed in detail previously ${ }^{1,10,31,32}$; however, the toxicity of such treatment, or the extent of immediate or long-term damage, remains an open question.

There are 2 modes of application of FE-DBD to the surface being treated: (1) the tissue or cells are used as a second active electrode, then plasma is bound between the dielectric surface of the powered electrode and the surface of the tissue being treated; or (2) plasma is separated from the tissue using a grounded metal mesh and gas is blown through the discharge to carry active species outside of the plasma. The first method is called direct application and the second indirect application of plasma to tissue. Fridman et $\mathrm{al}^{21}$ previously have shown that direct application of plasma yields to roughly an improvement in the rate of bacteria inactivation of 2 orders of magnitude compared with indirect application, even when the plasma is removed from the tissue by a fraction of a millimeter. ${ }^{21}$ All the effects of direct plasma on bacteria are negligible compared with the effects of charges. In short, leaving only ultraviolet (UV) radiation (removing plasma using quartz [UV] or magnesium fluoride [vacuum UV] windows) removes the ability of plasma to sterilize. Global gas temperature and applied electric fields are also negligible because the rise in gas temperature is insufficient to achieve sterilization and the frequency and waveform used is out of the range of effective electroporation (see refs. 1 and 33-35 for further details). The effects of neutral active species cannot be ignored. Given enough time, neutrals by themselves are able to sterilize as well as direct plasma treatment and they are responsible for many interesting biological effects, for example, the effect of nitric oxide in tissue regeneration. ${ }^{1,36,37}$ It is important to note here that the effect of plasma is on bacteria and not on the substrate: (1) agar treated by plasma for up to 1 hour remains able to grow bacteria the same way untreated agar does, and bacteria seem to be unaffected; and (2) bacteria treated on one Petri dish and transferred to another immediately after the treatment remain inactivated and do not grow.

\section{B. Setup for Raman Measurements}

The SWOrRD apparatus includes a tunable optical parametric oscillator pumped by a Q-switched, frequency-tripled, Nd:YAG, diode-pumped, solid-state laser at a rate of 1 $\mathrm{kHz}$. Signal and idler optical parametric oscillator outputs are continuously tunable from 420 to $700 \mathrm{~nm}$ and 715 to $2200 \mathrm{~nm}$, respectively. In addition, frequency-doubled signal output covers a range of 210 to $350 \mathrm{~nm}$ in deep UV light. Laser power is monitored before each spectrum is obtained. Exposure times at each wavelength are automatically adjusted to maintain constant exposure (time-integrated intensity) on the sample. Selected illuminating wavelengths may be in any order and need not be sequential. Light scattered from the illuminated sample may be collected at an angle of 180 degrees (backscatter) or 90 degrees with respect to incident laser beam. The scattered light is focused onto the entrance slit of an Acton double spectrometer (Princeton Instruments, Princeton, NJ, USA) consisting of two 0.5 -meter stages with a selection of gratings. A 


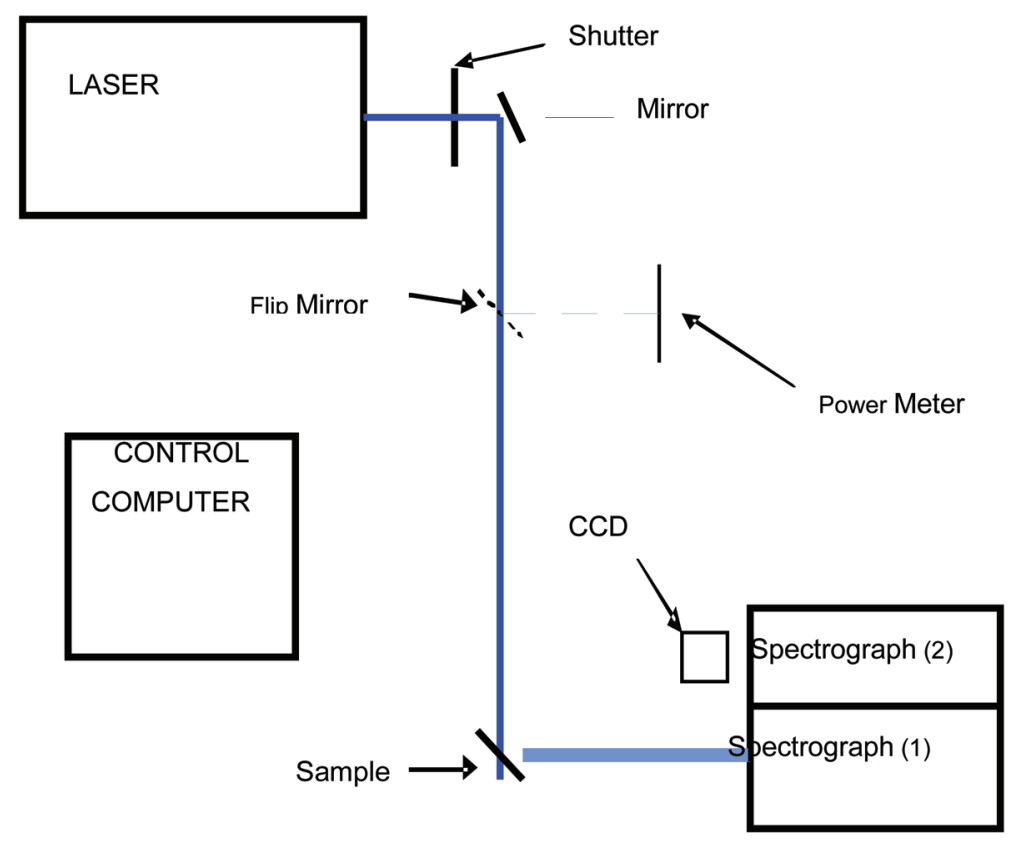

FIGURE 1. Block diagram of the experimental SWOrRD setup. CCD, charge-coupled device.

Pixis charge-coupled device camera (Princeton Instruments, Trenton, NJ, USA), back illuminated and coated for enhanced UV response, provides detection of the dispersed light. Data acquisition, laser tunability, and spectrograph operation are computer controlled. Data can be acquired using excitation wavelengths between 210 and $320 \mathrm{~nm}$ and 420 and $650 \mathrm{~nm}$. The average power from the laser is 5 to $20 \mathrm{~mW}$ for the deep UV range and 50 to $200 \mathrm{~mW}$ for visible range. A block diagram of the experimental setup is shown in Fig. 1. For this study, Raman data was obtained at 8 excitation wavelengths in the 220- to $260-\mathrm{nm}$ range. The integration time for each spectrum was $1200 \mathrm{~mW} / \mathrm{sec}$.

\section{Sample Growth, Preparation, and Measurement}

E. coli (American Type Culture Collection 11775) was grown in a shaker culture overnight at $37^{\circ} \mathrm{C}$. Thirty microliters of overnight culture was spread uniformly on nutrient agar plates and incubated overnight at $37^{\circ} \mathrm{C}$. The plates were removed from the incubator, sealed with parafilm, and shipped to Drexel University for plasma treatment. The treated samples together with control plates were shipped back to Naval Research Laboratory.

Circular sections of agar plates were cut and used for plasma treatment (Fig. 2). The agar slices were scraped gently with the addition of phosphate-buffered saline. The suspensions were further diluted with phosphate-buffered saline, placed in a capped 


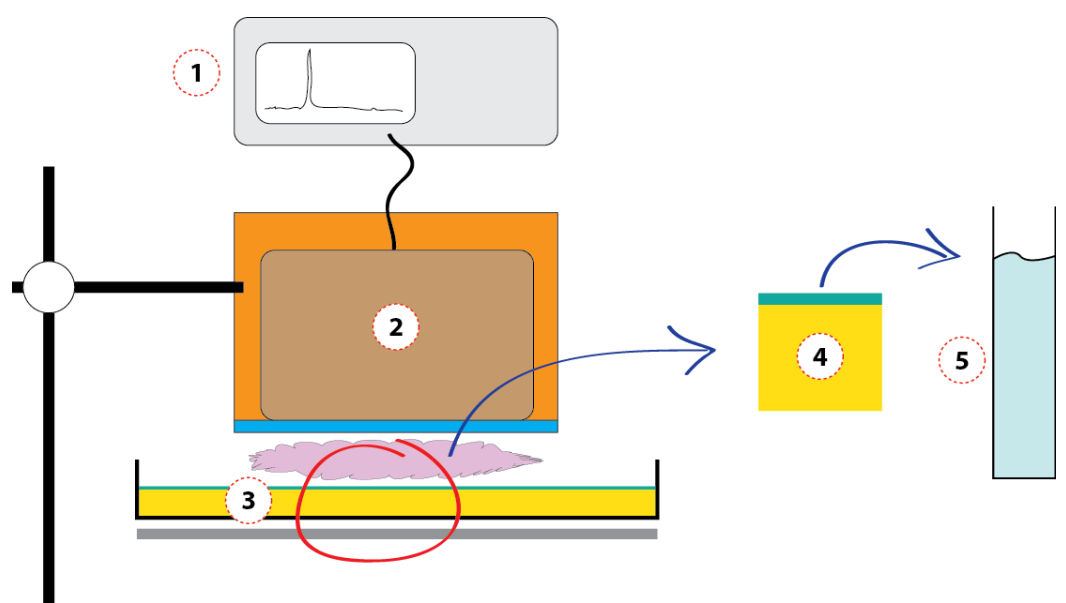

FIGURE 2. Schematic of the pulsed FE-DBD plasma treatment and sample preparation. A high-voltage pulse (1) is applied to the FE-DBD electrode (2); then plasma is generated between the powered electrode and bacteria-covered agar dish (3) placed on a grounded metal plate; after the treatment, bacteria from the agar sample (4) are scraped with the addition of phosphate-buffered saline and finally are transferred into a quartz cuvette (5) for SWOrRD analysis.

quartz cuvette, and used for Raman measurements on SWOrRD. The final absorbances of the measured suspensions were 0.82 and 0.79 at $600 \mathrm{~nm}$ for the plasma-treated and control samples, respectively, as measured by an Agilent 8453 spectrophotometer (Agilent Technologies, Santa Clara, CA, USA).

Serial dilutions and colony counts were used to obtain concentration values of the suspension before plasma treatment. The concentration of the control sample used for Raman measurement was $2.2 \times 10^{9}$ colony-forming units $/ \mathrm{mL}$. Samples that were treated by plasma did not form any colonies, indicating complete bacterial inactivation, as was reported previously by Fridman et al. ${ }^{10}$ Plasma-treated and untreated samples were measured on the same day to ensure identical experimental conditions.

\section{Data Processing}

The raw spectra were Fourier filtered to remove high-frequency noise at baseline and were recalibrated to compensate for power variation, sample absorption, wavelength drifts, system transmission, and detector responses. Spectra were normalized to the water peak at $\sim 3400 \mathrm{~cm}^{-1}$. All data processing was performed using MATLAB software (MathWorks, Natick, MA).

\section{RESULTS AND DISCUSSION}

Raman spectra of plasma-treated E. coli showed significant differences in both spectral 
A

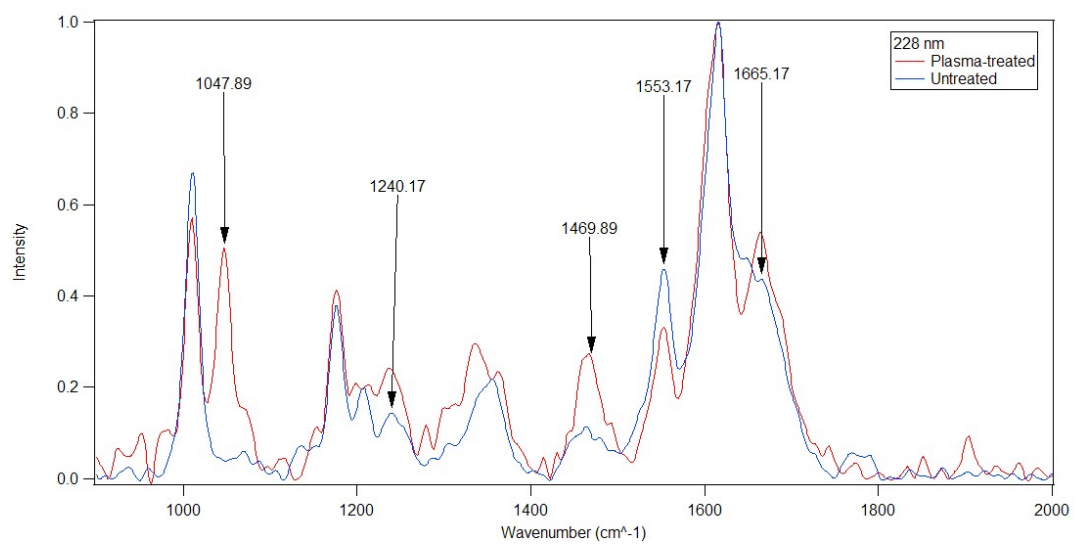

B

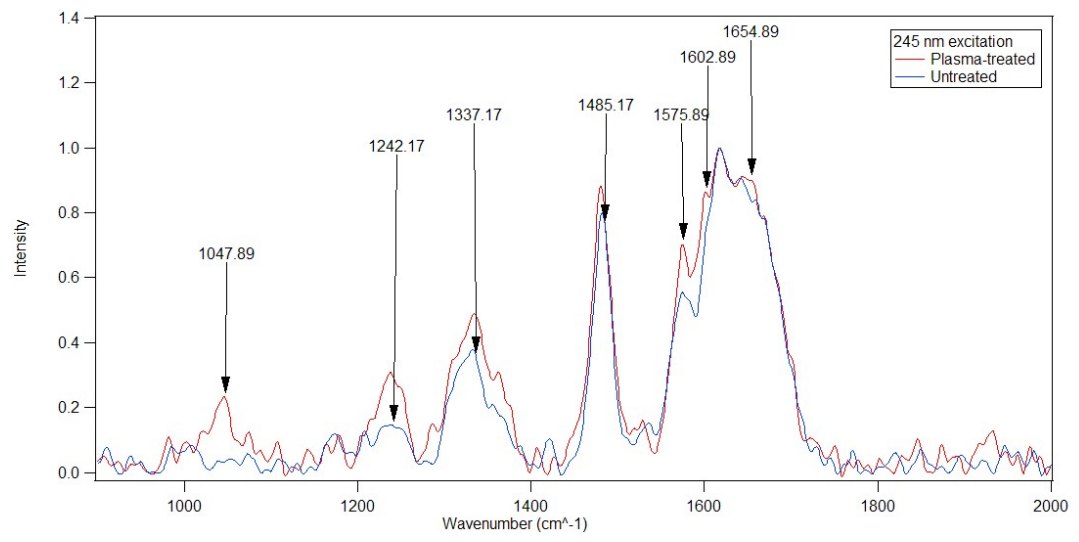

FIGURE 3. Comparison of Raman spectra of plasma in activated and untreated samples are shown at (a) $228 \mathrm{~nm}$ and (b) $245 \mathrm{~nm}$ excitation.

shape and relative amplitude compared with the untreated samples. A difference of almost $40 \%$ was observed in the $1609 \mathrm{~cm}^{-1}$ peak at 224-nm excitation. To understand the relative changes in Raman peaks between treated and untreated samples, the spectra were normalized to the intensity of the tallest peak in the $900-2000-\mathrm{cm}^{-1}$ region and examined for differences. Comparisons at 228-nm and 245-nm excitation are shown in Fig. 3(a) and (b).

At 228 -nm excitation, the plasma-treated cells have a strong peak at $\sim 1048 \mathrm{~cm}^{-1}$, which is strong at excitation wavelengths less than $245 \mathrm{~nm}$. This peak is attributed to glycogen, which is an energy storage molecule present in bacterial cytoplasm. Plasmatreated cells also exhibit a relative increase in the peak at $\sim 1242 \mathrm{~cm}^{-1}$, which has been variously attributed to amide III in $\beta$-sheet and random coils ${ }^{38}$ and to the nucleic acidbase uracil. ${ }^{39}$ The peaks at $1337 \mathrm{~cm}^{-1}$ have been attributed to the ring-breathing modes in adenine and guanine nucleic acid-bases in $E$. coli $i^{8}$ and various vibrational modes of $\mathrm{CH}_{2} / \mathrm{CH}_{3}$ present in lipids, nucleic acids, and proteins. ${ }^{8}{ }^{89}$ In contrast, the adenine/guanine 
contribution to the peak at $1485 \mathrm{~cm}^{-1}$ shows only a smaller increase in plasma-treated cells.

There is a relative increase in the proline peak at $\sim 1467 \mathrm{~cm}^{-1}$ in plasma-treated cells compared with the control group. Plasma-treated cells had decreased intensity of Raman peaks at $1010 \mathrm{~cm}^{-1}$ and $1553 \mathrm{~cm}^{-1}$ at 228-nm excitation; these peaks arise from the protein amino acids tyrosine and tryptophan, respectively. Changes in both shape and relative intensity also were observed at various regions of the broad peak at 1575, 1602, 1655 , and $1665 \mathrm{~cm}^{-1}$. These peaks are primarily due to amide I of protein, with some contribution from phenylalanine and the DNA bases guanine and adenine.

Overall, Raman spectra of plasma-treated cells differ from spectra of untreated cells over the entire fingerprint region of 900 to $1800 \mathrm{~cm}^{-1}$. Previous findings indicate that the primary target of plasma treatment is the cell membrane. Charged species cause membrane phospholipid and polysaccharide peroxidation, ${ }^{23}$ which lead to the activation of intracellular pathways, resulting in DNA damage. ${ }^{40}$

Additional measurements are essential to verify that these changes are reproducible. These preliminary measurements suggest that plasma-treated cells can be identified and classified by employing previously tested Naval Research Laboratory algorithms. ${ }^{8,9}$ Future work should include making additional measurements and assembling a spectral library of typical background signatures.

\section{CONCLUSIONS}

Multiwavelength, resonance-Raman spectroscopy was able to distinguish FE-DBD plasma-treated $E$. coli from untreated bacteria. The inability of plasma-treated bacteria to form colonies indicates complete deactivation by plasma irradiation.

Potential applications of this technology lie in decontamination and dosage monitoring for wound healing and water and surface treatments. Crucial to these applications are the speed and sensitivity of Raman measurements.

\section{REFERENCES}

1. Fridman G, Friedman G, Gutsol A, Shekhter AB, Vasilets VN, Fridman A. Applied plasma medicine. Plasma Process Polym. 2008;5:503-533.

2. Laroussi M. Low-temperature plasmas for medicine? IEEE Trans Plasma Sci. 2009;37:714-725.

3. Scholtz V. Julak J, Kriha V. The microbicidal effect of low-temperature plasma generated by corona discharge: comparison of various microorganisms on an agar surface or in aqueous suspension. Plasma Process Polym. 2010;7:237-243.

4. Cheruthazhekatt S, Cernak M, Slavicek P, Havel J. Gas plasmas and plasma modified materials in medicine. J Appl Biomed. 2010;8:55-66.

5. Martines E, Zuin M, Cavazzana R, Gazza E, Serianni G, Spagnolo S, Spolaore M, 
Leonardi A, Deligianni V, Brun P, Aragona M, Castagliuolo I, Brun P. A novel plasma source for sterilization of living tissues. New J Phys. 2009;11:115014.

6. Dobrynin D, Fridman G, Rieger J, Wynosky M, Rest R, Mukhin Y, Fridman A. Elimination of B. anthracis spores using dielectric barrier discharge plasma [Abstract]. In: IEEE International Conference on Plasma Science - Abstracts, 2009. ICOPS 2009. 1-5 June 2009.

7. Dobrynin D, Fridman G, Friedman G, Fridman A. Penetration deep into tissues of reactive oxygen species generated in floating-electrode dielectric barrier discharge (FE-DBD): in vitro agarose gel model mimicking an open wound. Plasma Med. Submitted.

8. Grun J, Bowles J, Gillis D, Kunapareddy P, Lunsford R, Manka CK, Nikitin S, Zheng W. Tunable multi-wavelength resonance-Raman detection of bacteria and chemicals in complex environments. Proc SPIE 2010;7687-96.

9. Grun J, Manka CK, Nikitin S, Zabetakis D, Comanescu G, Gillis D, Bowles J. Identification of bacteria from two-dimensional resonant-Raman spectra. Anal Chem. 2007;79:5489-5493.

10. Fridman G, Peddinghaus M, Balasubramania M, Ayan H, Fridman A, Gutsol A, Brooks A. Blood coagulation and living tissue sterilization by floating-electrode dielectric barrier discharge in air. Plasma Chem Plasma Process. 2006;26:425-442.

11. Fridman G, Shereshevsky A, Jost MM, Brooks AD, Fridman A, Gutsol A, Vasilets V, Friedman G. Floating electrode dielectric barrier discharge plasma in air promoting apoptotic behavior in melanoma skin cancer cell lines. Plasma Chem Plasma Process. 2007;27:163-176.

12. Chirokov, A., et al., Self-organization of microdischarges in dielectric barrier discharge plasma. IEEE Trans Plasma Sci. 2005;33:300-301.

13. Chirokov A, Gutsol A, Fridman A, Sieber K, Grace J, Robinson K. A study of twodimensional microdischarge pattern formation in dielectric barrier discharges. Plasma Chem Plasma Process. 2006;26:127-135.

14. Fridman A, Chirokov A, Gutsol A. Non-thermal atmospheric pressure discharges. J Phys D Appl Phys. 2005;38:R1-R24.

15. Ayan A, Fridman G, Gutsol AF, Vasilets VN, Fridman A, Friedman G. Nanosecondpulsed uniform dielectric-barrier discharge. IEEE Trans Plasma Sci. 2008;36:504508.

16. Ayan A, Fridman G, Staack D, Gutsol AF, Vasilets VN, Fridman AA, Friedman G. Heating effect of dielectric barrier discharges for direct medical treatment. IEEE Trans Plasma Sci. 2009;37:113-120.

17. Gutsol A, Vaze ND, Arjunan KP, Gallagher MJ Jr, Yang Y, Zhu J, Vasilets VN, Fridman A. Plasma for air and water sterilization. In: Selçuk G, Fridman A, eds. PlasmaAssisted Decontamination of Biological and Chemical Agents. Cesme-Izmir, Tur- 
key: Springer; 2008. p. 21.

18. Cooper M, Fridman G, Staack D, Gutsol AF, Vasilets VN, Anandan S, Cho YI, Fridman A, Tsapin A. Decontamination of surfaces from extremophile organisms using nonthermal atmospheric-pressure plasmas. IEEE Trans Plasma Sci. 2009;37:866871.

19. Gallagher MJ, Vaze N, Gangoli S, Vasilets VN, Gutsol AF, Milovanova TN, Anandan S, Murasko DN, Fridman AA. Rapid inactivation of airborne bacteria using atmospheric pressure dielectric barrier grating discharge. IEEE Trans Plasma Sci. 2007;35:1501-1510.

20. Gutsol A, Vaze ND, Arjunan KP, Gallagher MJ Jr, Yang Y, Zhu J, Vasilets VN, Fridman A. Plasma for air and water sterilization. In: NATO Advanced Study Institute (ASI), Plasma-Assisted Decontamination of Biological and Chemical Agents, Çesme, Turkey, 2007.

21. Fridman G, Brooks AD, Balasubramanian M, Fridman A, Gutsol A, Vasilets VN, Ayan H, Friedman G. Comparison of direct and indirect effects of non-thermal atmospheric pressure plasma on bacteria. Plasma Process Polym. 2007;4:370-375.

22. Kalghatgi SU, Fridman G, Cooper M, Nagaraj G, Peddinghaus M, Balasubramanian M, Vasilets VN, Gutsol AF, Fridman A, Friedman G. Mechanism of blood coagulation by nonthermal atmospheric pressure dielectric barrier discharge plasma. IEEE Trans Plasma Sci. 2007;35(5 Part 2):1559-1566.

23. Dobrynin D, Fridman G, Friedman G, Fridman A. Physical and biological mechanisms of direct plasma interaction with living tissue. New J Phys. 2009;11:115020.

24. Dobrynin D, , Fridman G, Friedman G, Fridman A. Toxicity of low temperature plasma treatment of living tissue. Presented at the Drexel IEEE Graduate Forum, Technical Poster Symposium, Philadelphia, PA, 2009. .

25. DobryninD, Wu A, Kalghatgi S, Park S, Shainsky N, Wasko K, Dumani E, Ownbey $\mathrm{R}$, Joshi S, Resesnig R, Brooks AD. Live pig skin tissue and wound toxicity of cold plasma treatment. Plasma Med. 2011;1:93-108.

26. Yost, A, Joshi S, Cooper M, Vaze N, Fridman G, Friedman G, Fridman A. Cold plasma inactivation of bacteria on dry or wet surfaces: mechanisms of DNA mutation and peroxidation of phospholipids. Presented at Drexel University Research Day, Philadelphia, PA, 2009.

27. Kalghatgi S, Friedman G, Fridman A, Clyne AM. Endothelial cell proliferation is enhanced by low dose non-thermal plasma through fibroblast growth factor-2 release. Ann Biomed Eng. 2010;38:748-757.

28. Vasilets VN, Tikchomirov LA, Ponomarev AN. The study of continuous HF low pressure discharge plasma action on the polyethylene surface. High Energy Chem. 1981;15:77-81.

29. Baydarovtsev YP, Vasilets VN, Ponomarev AN. The influence of gas nature on the 
rate of radical accumulation in teflon during low pressure glow discharge treatment. Russ J Chem Phys 1985;4:89-96.

30. Cooper M, Yang T, Fridman G, Ayan H, Vasilets VN, Gutsol A, Friedman G, Fridman A. Uniform and filamentary nature of continuous-wave and pulsed dielectric barrier discharge plasma. In: Selçuk G, Fridman A, eds. Plasma-Assisted Decontamination of Biological and Chemical Agents. Cesme-Izmir, Turkey: Springer; 2008. p.

31. Pesnel S, Vandamme M, Lerondel S, Le Pape A, Robert E, Dozias S, Barbosa E, Pouvesle J. Antitumor effect of plasma exposure: preliminary results in a mouse model, Presented at the 2nd International Conference on Plasma Medicine (ICPM2), San Antonio, Texas, March 16-20, 2009.

32. Laroussi M, Lu X. Room-temperature atmospheric pressure plasma plume for biomedical applications. Appl Phys Lett. 2005;87:113902.

33. Schoenbach K, Barker R, Liu S. Special issue on nonthermal medical/biological treatments using electromagnetic fields and ionized gases. IEEE Trans Plasma Sci. 2000;28:2-5.

34. Kotov YA, Sokovnin SY. Overview of the application of nanosecond electron beams for radiochemical sterilization. IEEE Trans Plasma Sci. 2000;28:133-136.

35. Kolb JF, Kong MG, Blackmore PF. Special issue on nonthermal medical/biological applications using ionized gases and electromagnetic fields. IEEE Trans Plasma Sci. 2006;34:1250-1252.

36. Shekhter AB, Kabisov RK, Pekshev AC, Kozlov NP, Perov YL. Experimental and clinical validation of plasmadynamic therapy of wounds with nitric oxide. Bull Exp Biol Med. 1998;126:829-834.

37. Shekhter AB, Serezhenkov CA, Rudenko TG, Pekshev AV, Vanin AF. Beneficial effect of gaseous nitric oxide on the healing of skin wounds. Nitric Oxide. 2005;12:210-219.

38. Britton KA, Dalterio RA, Nelson WH, Britt D, Sperry JF. Ultraviolet resonance Raman spectra of Escherichia coli with 222.5-251.0 nm pulsed laser excitation. Appl Spectrosc. 1988;42:782-788.

39. Movasaghi Z, Rehman S, Rehman DIU. Raman spectroscopy of biological tissues. Appl Spectrosc Rev. 2007;42:493-541.

40. Kalghatgi S, Kelly CM, Cerchar E, Torabi B, Alekseev O, Fridman A, Friedman G, Azizkhan-Clifford J. Effects of non-thermal plasma on mammalian cells. PLoS One. 2011;6:e16270. 